\title{
Central polar cap convection response to short duration southward Interplanetary Magnetic Field
}

\author{
P. T. Jayachandran, J. W. MacDougall \\ Department of Electrical Engineering, University of Western Ontario, London, Ontario, Canada, N6A5B9
}

Received: 14 April 1998 / Revised: 3 April 2000 / Accepted: 17 April 2000

\begin{abstract}
Central polar cap convection changes associated with southward turnings of the Interplanetary Magnetic Field (IMF) are studied using a chain of Canadian Advanced Digital Ionosondes (CADI) in the northern polar cap. A study of 32 short duration $(\sim 1 \mathrm{~h})$ southward IMF transition events found a three stage response: (1) initial response to a southward transition is near simultaneous for the entire polar cap; (2) the peak of the convection speed (attributed to the maximum merging electric field) propagates poleward from the ionospheric footprint of the merging region; and (3) if the change in IMF is rapid enough, then a step in convection appears to start at the cusp and then propagates antisunward over the polar cap with the velocity of the maximum convection. On the nightside, a substorm onset is observed at about the time when the step increase in convection (associated with the rapid transition of IMF) arrives at the polar cap boundary.
\end{abstract}

Key words: Ionosphere (plasma convection; polar ionosphere) - Magnetospheric physics (solar wind - magnetosphere interaction)

\section{Introduction}

A number of observations over the past two decades have shown that the plasma flow in the Earth's polar ionosphere is driven by the solar wind-magnetosphericionospheric coupling. The nature of this coupling and the resultant plasma flow in the high-latitude ionosphere depends on the orientation and strength of the Interplanetary Magnetic Field (IMF). Numerous observations using different techniques (e.g., Mozer and Lucht, 1974; Heppner, 1977; Heelis, 1984; Friis-Christensen et al., 1985; Foster et al., 1986; Heppner and Maynard,

Correspondence to: $\mathrm{P}$. T. Jayachandran
1987; Senior et al., 1990; Cannon et al., 1991; Ruohoniemi and Greenwald, 1995a, b; Rich and Hairston, 1994) and theoretical as well as empirical models (Heelis, 1984; Heppner and Maynard, 1987; Lockwood et al., 1990; Weimer, 1995, 1996) have increased our knowledge of the nature of the high-latitude ionospheric convection for different orientations of the IMF. However, the nature of the overall convection response to short duration of southward IMF conditions is not well understood and explored.

Most of the previous studies (Todd et al., 1998; Etamadai et al., 1988; Saunders et al., 1992; Ridley et al., 1998; Ruohoniemi and Greenwald, 1998) were either confined to auroral regions (closed field lines) or regions near to the polar cap boundary. Some of these have shown that the high-latitude convection responds with a delay after southward transition of IMF (Etamadi et al., 1988; Todd et al., 1988), although there are significant differences in the measured delays. Ruohoniemi and Greenwald (1998) using SuperDARN convection measurements and Ridley et al. (1998) using magnetometer and AMIE technique (Richmond and Kamide, 1988) infer that the entire high-latitude convection changes almost simultaneously. However, the exact nature of the flow response is a subject of debate (Lockwood and Cowley, 1999; Ridley et al., 1999).

Based on these previous studies, there are two schools of thought pertaining to the ionospheric convection response to the southward transition of IMF. They are: (1) near simultaneous response of the entire convection pattern (by magnetosonic waves) (Ridley et al., 1998) or, (2) delayed response due to the propagation of the convection change (in the form of two cell pattern) from the cusp (Cowley and Lockwood, 1992). A study by Saunders et al. (1992) using the CANOPUS magnetometer array has shown the flow response was first initiated near the noon sector and spreads towards the dawn and dusk sector with longitudinal phase velocity of the order of $5 \mathrm{~km} / \mathrm{s}$. This pattern of change agrees with the theory of Cowley and Lockwood (1992). Recently Shepherd et al. (1999) came up with a suggestion, based on 
observation, that the entire dayside magnetosphere is draped by the IMF, thereby producing near simultaneous response.

Within the polar cap there has not been much information about the exact nature of convection response. It has been suggested that the convection changes in the central polar cap depend on the both the dayside and night side reconnections (Lockwood et al., 1990). Their model shows high-latitude convection driven jointly by reconnection on the dayside (associated with an expanding polar cap) and by the tail reconnection on the nightside (associated with a contracting polar cap). Siscoe and Huang (1985) derived quantitative model for these flows. In their model they have assumed that flux is transferred from closed field lines of the dayside auroral zone into the open field lines of the polar cap across a restricted sector of the polar cap boundary near noon, with no flow across the boundary at other LMT. The cusp region moves equatorward as the polar cap expands.

In this work, we present a revised pattern of convection response, based on the observation from a chain of Canadian Advanced Digital Ionosondes (CADIs) situated within the polar cap. We find that the central polar cap convection changes associated with short duration southward turning of IMF has 3 components: (1) an initial response to a southward transition that is nearly simultaneous for the entire polar cap, (2) a peak of convection speed (attributed to the maximum merging electric field) that propagates poleward from the ionospheric footprint of the merging region and, if the change in IMF is rapid enough, and (3) a step in convection that appears to start at the cusp and then propagates antisunward over the polar cap with velocity of the maximum convection.

\section{Observations}

A chain of Canadian Advanced Digital Ionosondes (CADI) has been operational in the Canadian Arctic since 1993. The stations used in this study are Eureka (Geographical latitude $79.9^{\circ} \mathrm{N}$, longitude $85.92^{\circ} \mathrm{W}$, $89^{\circ} \Lambda$ ), Resolute Bay $\left(74.75^{\circ} \mathrm{N}, 94.99^{\circ} \mathrm{W}, 83^{\circ} \Lambda\right)$ and Cambridge Bay $\left(69.10^{\circ} \mathrm{N}, 105.11^{\circ} \mathrm{W}, 79^{\circ} \Lambda\right)$ which are all in the polar cap region. Eureka is almost at the geomagnetic North Pole. These measurements have the advantage of complete temporal coverage and the chain of stations provides sufficient spatial coverage to show the nature of flows in the polar cap regions. CADI employs an antenna array consisting of four dipoles arranged along the side of a square of $60 \mathrm{~m}$ on each side, and has a receiver dedicated to each antenna. Doppler samples with 64 data points are obtained every $30 \mathrm{~s}$ and an ionogram of 95 frequencies every minute. From the Doppler measurements, at $3 \mathrm{MHz}$ and $4 \mathrm{MHz}$, the convection velocity (speed and azimuth) and other echoe properties are derived. For the details of data analysis technique see Grant et al. (1995). The IMF and solar wind data used are from the WIND satellite.

We selected 32 southward turning events between January 1997-February 1999. These events are selected on the basis of the following criteria: (a) the IMF southward excursion should be $>30 \mathrm{~min}$ and the magnitude should be $>2 \mathrm{nT}$, and (b) CADI drifts should have small uncertainty.

\section{2 a Estimation of the delay from the IMF at WIND satellite to the ionosphere}

In order to look at the convection changes in response to an IMF turning we need to estimate the time when the IMF changes should arrive at the polar cap ionosphere. For almost all the cases studied here (except for two events in February 1999) WIND satellite was in the upstream solar wind. The time delay from the IMF change detected at the satellite and the arrival of the change at the ionosphere is a combination of three segments: (1) the time from the spacecraft to the subsolar bow shock $\left(t_{1}\right),(2)$ propagation time from the bow shock to the magnetopause $\left(t_{2}\right)$, and (3) the time from the magnetopause to the ionosphere $\left(t_{3}\right)$. The value for the communication time between the magnetopause and the ionosphere $\left(t_{3}\right)$ is taken to be 2 min representing the average Alfven wave travel time from the magnetosphere to the ionosphere. The time $t_{1}$ is give by $\left(X_{s w}-X_{b}\right) / V_{s}$. Where $X_{s w}$ is the point of intersection of the IMF with the GSE Sun-Earth axis, which is taken as the $X$-coordinate of the WIND satellite since the satellite was close to the Sun-Earth plane during these observations. $X_{b}$ is the bow shock radius and $V_{s}$ is the measured solar wind speed. The travel time across the magnetosheath $\left(t_{2}\right)$ is given by $\left(X_{b}-X_{\mathrm{m}}\right) / V_{s h}$. Where $X_{m}$ is the sub-solar magnetopause radius and $V_{s h}$ is the bulk velocity of the magnetosheath. Here we have assumed that $X_{b}=1.33 X_{m}$ (Fairfield, 1971) and $V_{s h}=0.125 V_{s}$ (Spreiter and Stahara, 1980) and $X_{m}=G /\left(n_{s w} V_{s}^{2}\right)^{1 / 6}$ where $n_{s w}$ is the solar wind particle density and $V_{s}$ is the solar wind velocity and $G=10750$ (Holzer and Salvin, 1982). The delay, $t_{1}+t_{2}+t_{3}$, is used as an adjustment to the IMF times that will be shown later. We have also estimated the delays using other methods proposed by Ridley et al. (1998) and obtained similar values.

\section{$2 b$ Convection responses in the central polar cap}

In this section we show four typical examples of the central polar cap convection response to short duration southward IMF transitions. Figure 1 shows the IMF and CADI measurements from Eureka for 22 March 1997 between 07:00-11:00 UT. The top panel shows the IMF, which is adjusted for the delay between the IMF change at the satellite and ionosphere as discussed. The solid line is the IMF $B_{z}$ and the dotted line is the IMF $B_{y}$. The middle panel shows the convection orientation (sunward and antisunward directions are indicated) and bottom panel shows the convection speed. The time history of the IMF shows that it was predominantly northward till 08:07 UT with magnitude of $\sim 6 \mathrm{nT}$. The convection was sunward (see middle panel of Fig. 1) in the polar cap as expected for strongly northward IMF 


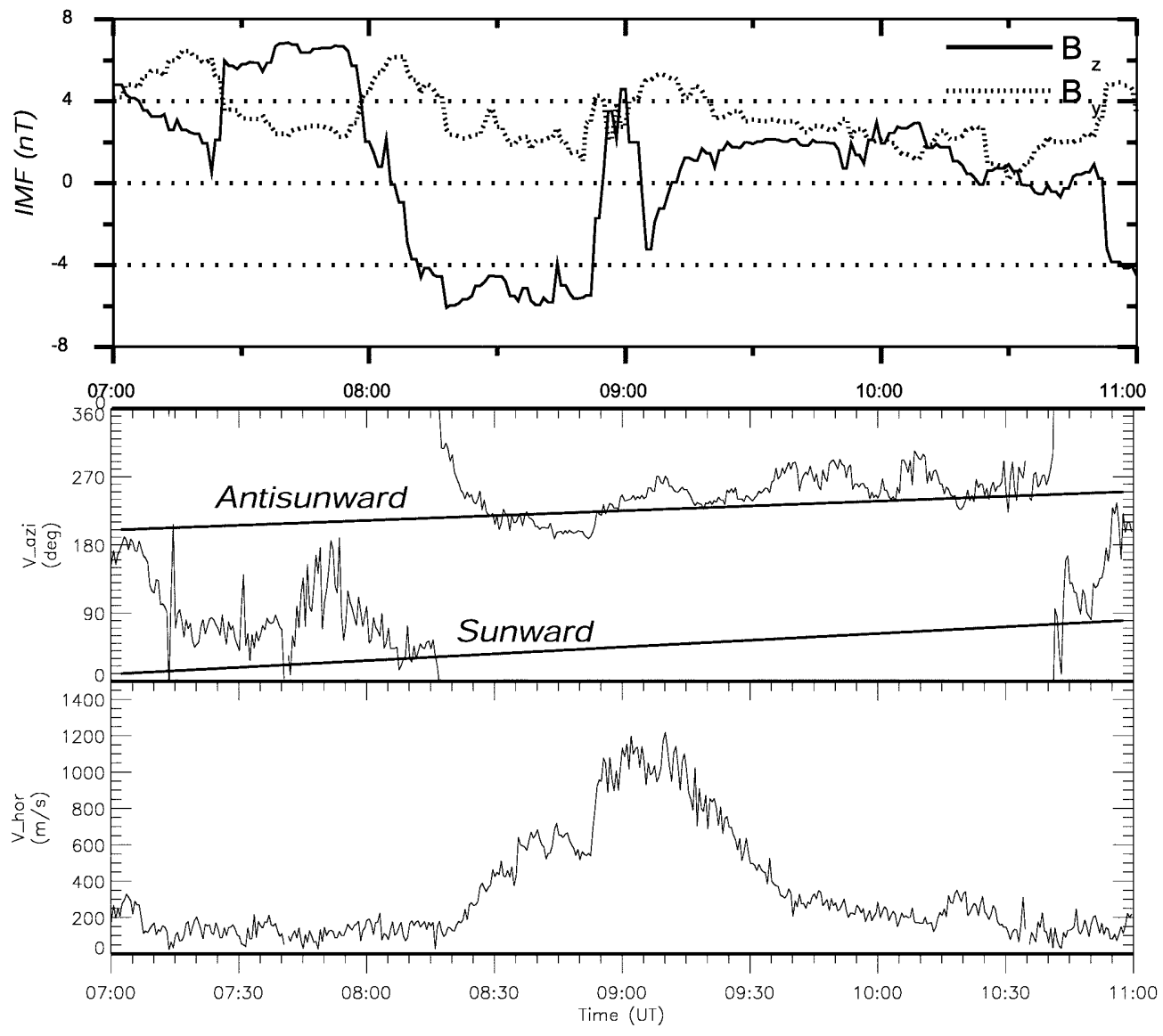

Fig. 1. Top panel: variation of IMF $B_{z}$ (solid line) and $B_{y}$ (dotted line). Middle panel: convection azimuth. Bottom panel: convection velocity at Eureka during 22 March, 1997. Lines in the middle panel show sunward and antisunward directions conditions and the convection speed was of the order of $100 \mathrm{~m} / \mathrm{s}$ (low speeds during northward IMF). The IMF turned to southward about 08:10 UT and the full excursion (from +6 to $-5 \mathrm{nT}$ ) took around $12 \mathrm{~min}$. The IMF remained southward till 09:00 UT. IMF $B_{y}$ was positive during the entire duration of the event with an average value of around $3.2 \mathrm{nT}$. At Eureka the convection, which was initially sunward, started turning antisunward at about 08:17 UT and became fully antisunward at $\sim 08: 25$. The convection speed increased starting at $\sim 08: 20$ (see Fig. 1). Using 08:20 as the time for the change from sunward to antisunward convection, the delay after the IMF southward turning (time adjusted for the ionosphere), to this initial response at Eureka was $10 \mathrm{~min}$. After the initial response the speed of the convection progressively increased. The convection speed increase was not a sudden increase, rather it showed a systematic increase from $100 \mathrm{~m} / \mathrm{s}$ to about $600 \mathrm{~m} / \mathrm{s}$ during the first $35 \mathrm{~min}$ after the change to antisunward convection. At 0855 UT there was a "step" increase in convection speed to a peak value of $\sim 1200 \mathrm{~m} / \mathrm{s}$. Note that near this time the IMF returned to northward (at 08:57 UT). However, the convection remained at its peak value for about $20 \mathrm{~min}$ before starting to decrease. The decrease took about $30 \mathrm{~min}$ or longer (depending at what time was chosen on Fig. 1) for the end of the convection event. The convection response at a central polar cap location, therefore, took about 83 min (or longer) for a southward IMF excursion of about $50 \mathrm{~min}$.
Another example for the convection response to the changes in IMF is given in Fig. 2. The figure shows the IMF (top panel) and convection speed (bottom panel) between 00:00-12:00 UT for 26 March, 1997. This example is shown because there was a one-to-one correlation between IMF $B z$ changes and convection response even for small events. There are as many as seven transitions (including the short duration events) in IMF and corresponding changes in convection. This shows that the central polar cap convection is a good indicator of changes of IMF even for very short duration transitions. The individual events are not as clear as was that in Fig. 1 so one cannot say whether the convection responses shows both a progressive component and a step component.

For the event shown in Fig. 1, the delay in the first identifiable response at Eureka relative to the time when the IMF changes should first impinge on the ionosphere was $10 \mathrm{~min}$, whereas, for the events shown in Fig. 2, there were small variations in the delay time between the change in IMF and convection response. The mean delay for these and other events (a total of 32 events) was $15 \pm 3$ min delay for an initial response in the central polar cap after the IMF change at the cusp ionosphere. This time is relatively long compared to the plot of ionospheric response times shown by Fig. 2 of Lockwood and Cowley (1999), therefore, the initial response time at the centre of the polar cap may be delayed by the order of 5 min relative to the cusp region. 

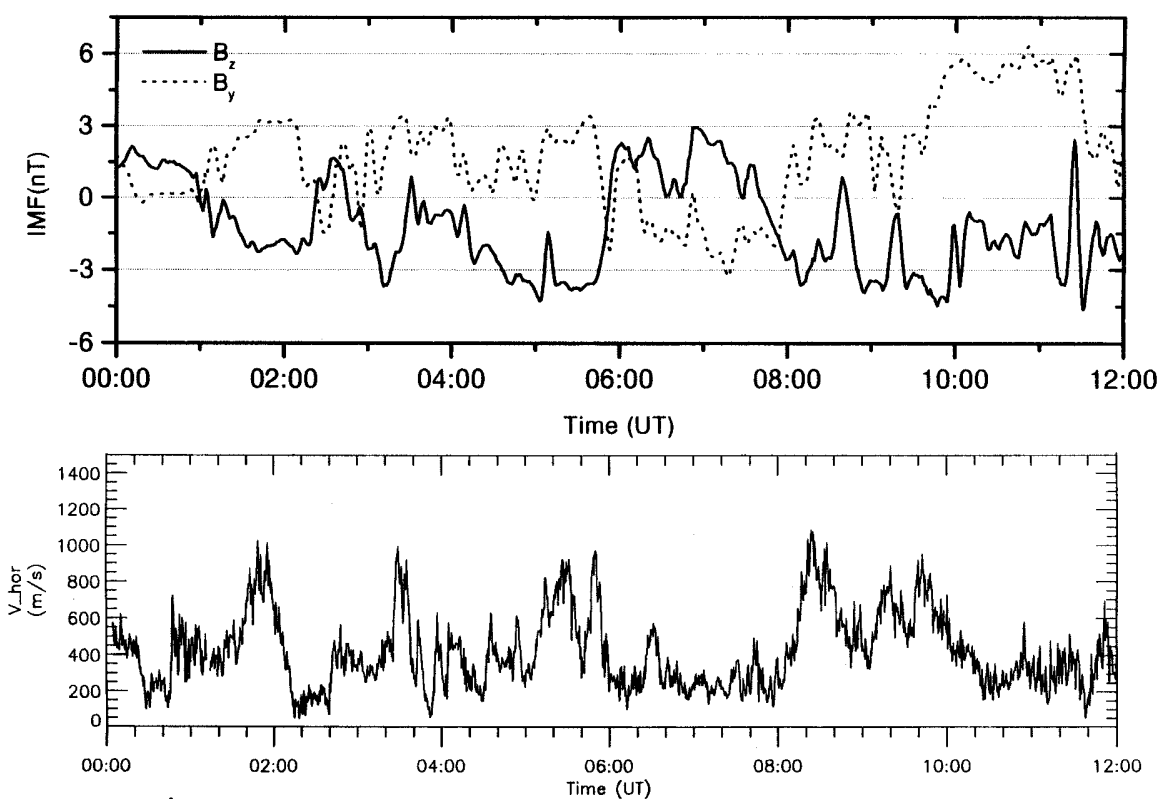

Fig. 2. Top panel: variation of IMF $B_{z}$ (solid line) and $B_{y}$ (dotted line). Bottom panel: convection velocity at Eureka during 26 March, 1997
In the previous section we have described the changes in convection at a central polar cap station in response to a southward turning of the IMF. In this section we will discuss the convection response using simultaneous 2-station data. The next two examples show the convection response at two polar cap stations: Eureka, which is very close to the geomagnetic pole and Resolute Bay, $622 \mathrm{~km}$ south of Eureka. During these events, WIND satellite was tailward of Earth and the time of the IMF was adjusted to the time when the IMF changes should first impinge on the ionosphere. There may be uncertainty in the adjusted time. However, our main interest here is to show the relative convection response at the two polar cap stations for a southward transition of the IMF. Figure 3 shows the variation of IMF (top panel) and convection at the two stations (bottom panel) between 10:00-16:00 UT (02:34-08:34 MLT) on 11 February, 1999. Note that the convection and the IMF are $2 \mathrm{~min}$ averages. There are four transitions in the IMF with corresponding changes in convection. These are marked by arrows in Fig. 3. In all four cases, the initial changes in convection are almost simultaneous at Resolute Bay and Eureka. However, there is a systematic delay in the arrival of peak of the convection at these two stations. The delays in the peak of the convection between Resolute Bay and Eureka were 4, 6, 16 and $10 \mathrm{~min}$ (calculated by crosscorrelation) for the first, second, third and fourth events respectively. For all these events the peak in convection was observed first at Resolute Bay and then at Eureka showing that the propagation is poleward. From these time delays the apparent phase velocity is highest for the first event $(\sim 2.5 \mathrm{~km} / \mathrm{s})$ and lower for later events. We interpret the higher velocity for the earlier events as an apparent phase velocity for a convection change propagating at an angle to the line joining the stations. Note that for the six hours shown, the relative location of Resolute Bay and Eureka changed significantly.

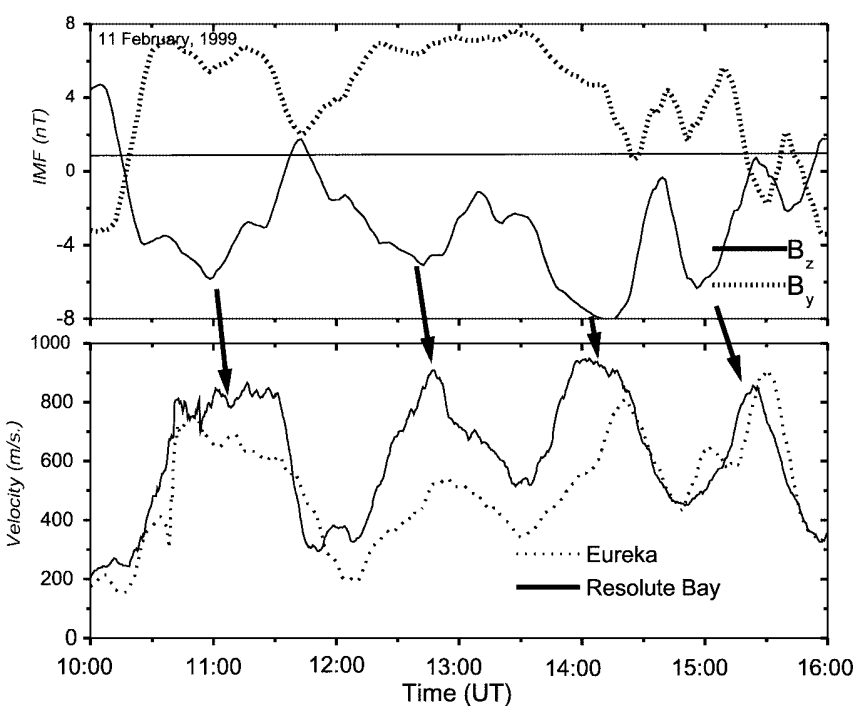

Fig. 3. Top panel: variation of IMF $B_{z}$ (solid line) and $B_{y}$ (dotted line). Bottom panel: convection velocity at Eureka (dotted line) and Resolute Bay (solid line) for 11 February, 1999. The convection velocity and IMF are $2 \frac{1}{2}$ min averages

Resolute Bay and Eureka are orientated approximately dawn-to-dusk of one another at 13:30 UT (between the second and third events), whereas for the first and second events Resolute was antisunward of Eureka, and for the third and fourth events it was sunward.

Figure 4 shows variation of IMF and convection at the two polar cap stations between 18:30-21:00 UT (11:00-13:30 MLT) for 12 February 1999. The top panel in the figure is the IMF (solid line is $B z$ and dotted line is $B y$ ) and the bottom panel is the convection velocity at Eureka (open circle and dotted line) and Resolute Bay (star symbol and solid line). The symbols represent the $30 \mathrm{~s}$ data points and the lines represent the $2 \frac{1}{2}$ min running average. IMF was northward between 


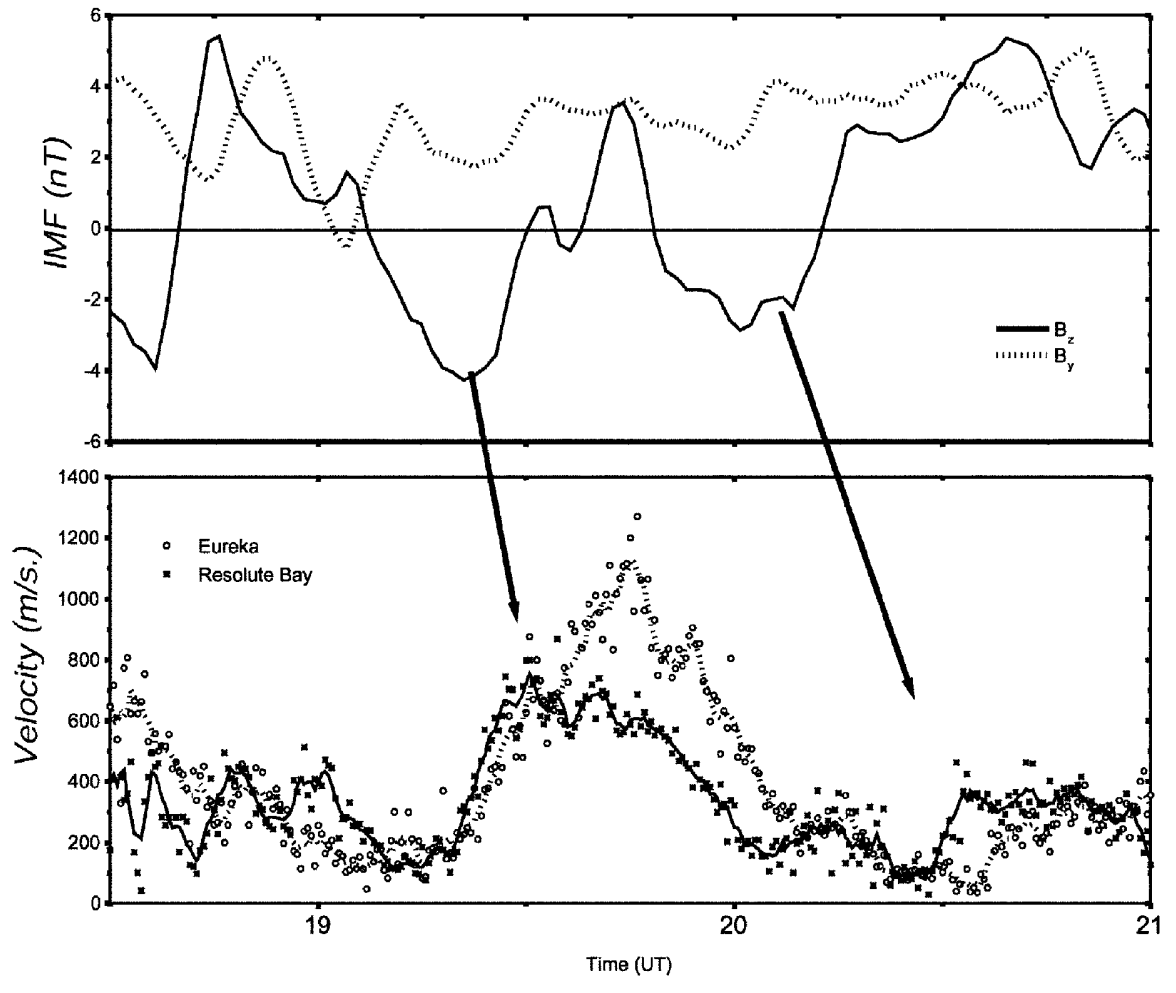

Fig. 4. Top panel: variation of IMF $B_{z}$ (solid line) and $B_{y}$ (dotted line). Bottom panel: convection velocity at Eureka (open circles) and Resolute Bay (* symbol) for 12 February, 1999. The solid line and dotted line in the bottom panel are the $2 \frac{1}{2}$ min averages of the convection
18:28 UT and 19:12 UT and convection speed was low. At 19:13 UT IMF turned southward and reached its minimum value of $-4.2 \mathrm{nT}$ at 19:22 UT. The initial response to the IMF turning was synchronous at the two stations. However, the peak in convection occurs earlier at Resolute Bay than at Eureka. The delay in the peak convection response between these two stations was $14 \mathrm{~min}$. There was another transition at 19:50, which also showed the same delay between these two stations. During these times Eureka was aligned almost exactly in the anti-sunward direction from Resolute Bay. Therefore, any changes in the convection propagating from the cusp region should be seen first at Resolute Bay, as was observed. The speed of propagation calculated from the time delay between the two stations is $740 \mathrm{~m} / \mathrm{s}$. This speed is comparable with the maximum convection speed for the first event shown in Fig. 4. Thus we infer that convection changes along a noon-midnight line running through the cusp appear to propagate over the polar cap with a speed close to the convection speed. Note that $740 \mathrm{~m} / \mathrm{s}$ is near the low end of the maximum convection speeds that will be shown in the next figure.

The relationship between the maximum convection speed and the corresponding minimum in IMF $B z$ during these 32 events is shown in Fig. 5 (some additional data points for northward IMF have been added to this figure to show the complete variation with IMF). This figure shows that the maximum convection velocity increases linearly as the negative value of IMF $B z$ increases. A linear regression analysis on these data points (for southward IMF conditions) gives the relationship between the IMF $B_{z}$ and convection as $V_{c o n}(\mathrm{~m} /$ $\mathrm{s})=-10-197 \times B_{z}(\mathrm{nT})$. This formula gives the

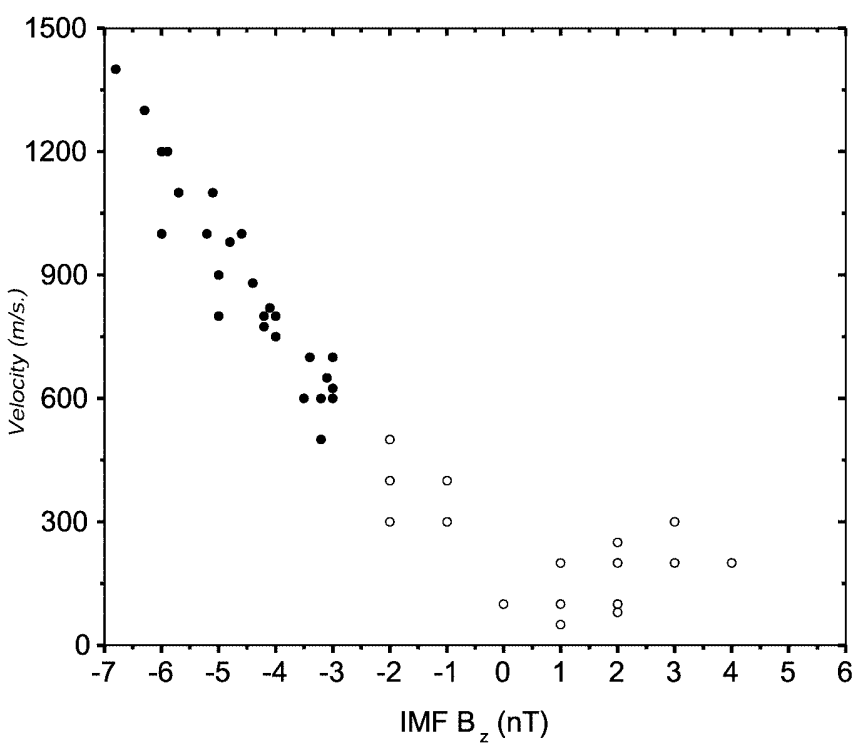

Fig. 5. Scatter plot showing the relationship between the peak convection velocity for the 32 events and the corresponding value of IMF $B_{z}$. The open circles are data points added for completeness of the figure from other days of steady convection measurements

maximum convection speed for these transient events. This figure also shows that the typical maximum convection speed for the events that we studied was $\sim 900 \mathrm{~m} / \mathrm{s}$.

\section{Discussion}

The only conceptual model that is available for the highlatitude convection response to the IMF southward 
turning is by Cowley and Lockwood (1992) which is basically based on the mathematical formulation by Siscoe and Huang (1985). This conceptual model (Cowley and Lockwood, 1992) of the polar cap response to short time $(\sim 1 \mathrm{~h})$ southward turnings of the IMF has a combination of two time dependant components, which are superimposed. One component is driven by the reconnection at the dayside magnetopause, while the other component is driven by the reconnection at the tail. Based on this two component hypothesis, Cowley and Lockwood (1992) predicted a pattern of central polar cap convection changes that can be compared with our observations. The variation of convection speed at Eureka shown in Fig. 1 is similar to their predicted pattern. However our observations appear to show some disagreement with their model since the maximum convection in the central polar cap appears to be reached before reconnection begins in the tail (see later).
To continue this discussion we show, in Fig. 6, a sequence of sketches of the flow responses that are compatible with our observations. The timings will be for the event shown in Fig. 1. Throughout this figure, the station locations R (Resolute Bay) and E (Eureka) are shown for noon LMT (i.e. the stations are aligned perfectly on the noon-midnight meridian). The sequence of sketches starts (Fig. 6a) with an equilibrium situation when IMF was northward for a significant interval of time during which no low latitude reconnection (conversion of closed flux to open flux) has occurred and there is weak sunward flow in the polar cap. We show the sunward boundary of the polar cap at $78^{\circ}$ (all latitudes in this discussion are magnetic) although we had no observational information to determine this latitude. On the nightside we show the polar cap openclosed field line boundary at $74^{\circ}$. Although we had no direct measurement of this boundary since there was

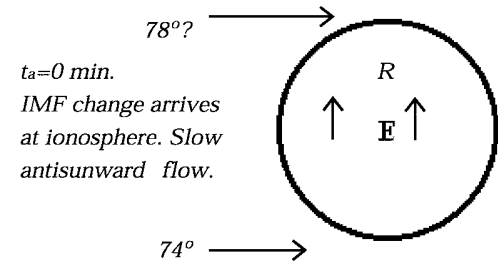

(a)

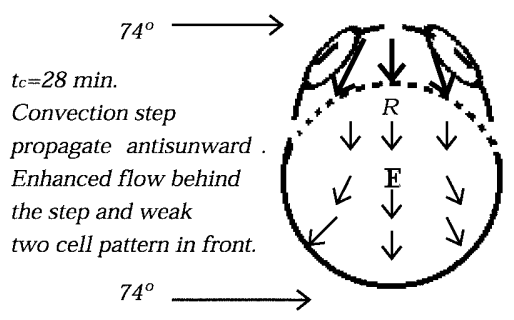

(c)

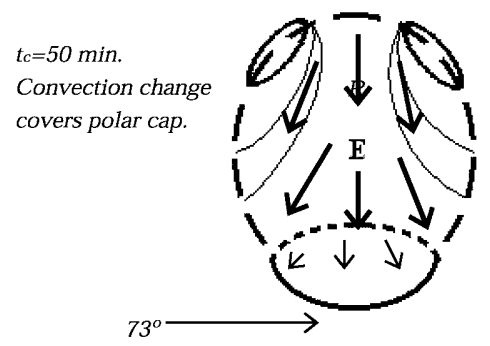

(e)

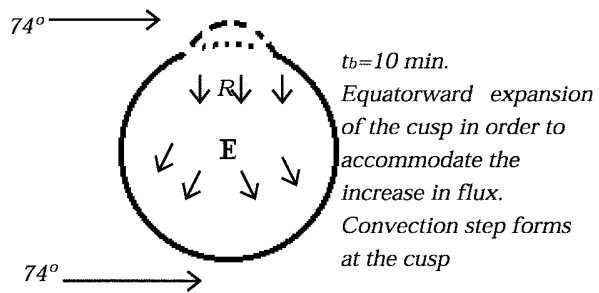

(b)

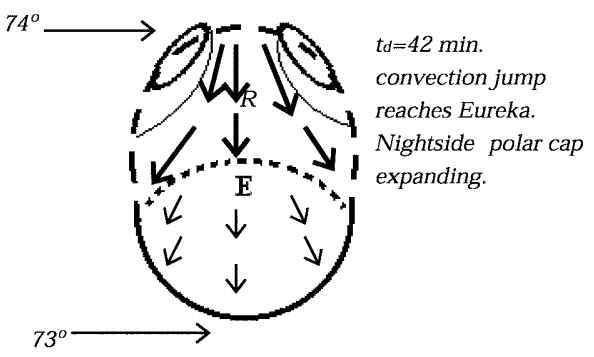

(d)

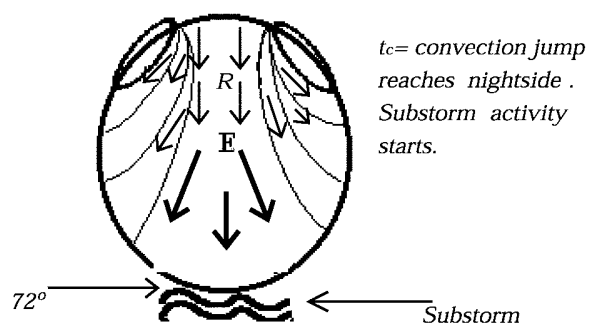

(f)

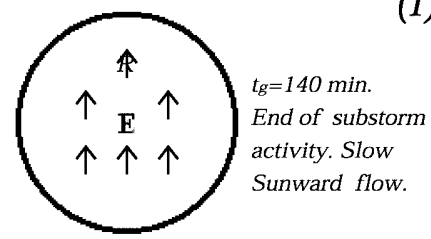

(g)
Fig. 6a-g. Schematic representation of the polar cap changes deduced from the observations. f Is deduced mainly from the observations of 22 March, 1997. $E$ and $R$ denote the location of Eureka and Resolute Bay with respect to the noon-midnight meridian (i.e., the stations are aligned perfectly in the noonmidnight direction) 
neither Northern Hemisphere DMSP particle data nor optical data at this time, there was a Southern Hemisphere DMSP pass at 0755 UT which showed the nightside polar rain boundary near $74^{\circ}$ magnetic latitude. Also $74^{\circ}$ is similar to the pre growth phase boundary latitudes shown in other substorm studies (e.g. Samson et al., 1992).

Figure $6 \mathrm{a}$ is the time when the IMF has just changed southward and the change has arrived at the cleft/cusp region ionosphere. This time is denoted by $t_{a}$. At this time reconnection starts at the dayside magnetopause and the open-closed field line boundary of the polar cap moves equatorward. We show this equatorward expansion of the dayside polar cap in Fig. $6 \mathrm{~b}$ as starting as a bulge that then expands rapidly along the boundary polar cap in subsequent sketches. We estimate the latitude of the cusp part of the bulge at about $73^{\circ}$ (see later for how we calculated this latitude). During the initial sunward expansion, shown in Fig. $6 \mathrm{~b}$, the reconnecting flux can be accounted for by the increase in size of the polar cap so that high antisunward flows are not required. We assume that this initial expansion time is of the order of $10 \mathrm{~min}$. This is based on our observations of the delay from our calculated arrival time of IMF changes at the ionosphere and the time when we saw a start to the polar cap convection changes at Eureka. Therefore we show the time as $t_{b}=t_{a}+10 \mathrm{~min}$.

At the end of this initial expansion, the flux that continues to reconnect must be accounted for by an antisunward convective flow, so a large antisunward convection must suddenly develop. We suggest a location for this convection step by the dotted line in Fig. 6b. The sequence of sketches will show the velocity step (dotted curve) propagating antisunward over the polar cap. We assume that a weak 2-cell convection appears at time $t_{b}$, and strengthens in subsequent sketches. The next sketches show progressive development of this 2-cell convection pattern, with some propagation of the strengthening pattern around the periphery of the polar cap. This propagation velocity on the periphery of the polar cap has been estimated to be of the order of several $\mathrm{km} / \mathrm{s}$ using different techniques (Etamadi et al., 1998; Todd et al., 1988; Saunders et al., 1992; Lockwood et al., 1992). Figure 6c shows the time $\left(t_{c}\right)$ when the step up to maximum velocity reaches Resolute Bay and Fig. $6 \mathrm{~d}$ shows the time $\left(t_{d}\right)$ when the velocity step reaches Eureka, near the centre of the polar cap. Our measurements show a typical time $t_{d}-t_{c} \approx$ 14 min for the travel time from Resolute to Eureka. Note that our sketches show the development of the convection pattern not as a feature that simply propagates from the cusp region, but as a developing 2-cell pattern that spreads in from the periphery of the cap. The inward propagation implied in Fig. 6d, e is drawn so that the changing patterns agree with the observed time delays between Resolute and Eureka when the stations have non-noon-midnight relative orientations as they did for Fig. 3. For Fig. 6d and the event of Fig. 1, the IMF now changes to northward again and the reconnection at the magnetopause now ceases and the dayside part of the 2-cell flow pattern starts to decline. This decline will be shown in Fig. 6e-g.

We next discuss the information that we have about the pattern of changes on the nightside, and which will be shown in the sketch Fig. 6e, f. We have a CADI station at lower latitudes (Cambridge Bay, $79^{\circ} \Lambda$, a distance of $\sim 1300 \mathrm{~km}$ south of Eureka) and for the event of Fig. 1 this was located antisunward from Eureka. Although this station had some technical problems at this time, it appeared to show that the velocity step continued to travel antisunward at about $1 \mathrm{~km} / \mathrm{s}$.

In the antisunward auroral region, for the event of Fig. 1, we have data from the SuperDARN Radar at Saskatoon, and the CANOPUS magnetometer array. There was no CANOPUS optical data or DMSP satellite data for the time of this event. SuperDARN showed an equatorward motion of a band of echoes that was seen at about $70^{\circ}$ latitude at the time of Fig. 6a, b. The expansion started at about $t=30 \mathrm{~min}$, and at the time of Fig. 6d it had moved equatorward by about $2^{\circ}$. This equatorward motion continued and ultimately, at the times of Fig. 6e and f, the band of echoes was near $67^{\circ}$. There have been several studies that compared SuperDARN echoes with nightside auroral boundaries (e.g. Lewis et al., 1997, 1998). A recent study by Voronkov et al. (1999) showed that the SuperDARN echoes tend to be collocated with the nightside proton auroral band. At substorm expansion phase onset the HF radar echoes were found to be at a latitude close to the substorm onset region. This is in agreement with our observation since, at the time of Fig. 6f (09:25 UT) we observed the start of substorm activity at $67^{\circ}$ latitude as indicated by the CANOPUS magnetometer network. The $\mathrm{H}$ component of the magnetograms of part of the CANOPUS magnetometer array for 22 March 1997 (the day shown in Fig. 1) between 07:00-11:00 UT is shown in Fig. 7. The magnetometers are for five stations, all near 67\%: DAWS (Dawson, 65.67 $\Lambda$ ), FSIM (Fort Simpson, $67.52^{\circ} \Lambda$ ), FSMI (Fort Smith, $67.88^{\circ} \Lambda$ ), RABB (Rabbit Lake, $67.69^{\circ} \Lambda$ ) and GILL (Gillam, 67.20 ${ }^{\circ} \Lambda$ ). These stations are near local midnight and thus suitably located for substorm detection. All the stations show magnetic substorm activity starting around 09:25 UT. The event was also identified as a substorm using the geosynchronous (LANL satellite) particle data and AE index.

It is not clear whether the substorm trigger was the northward turning about 09:00 UT that can be observed in the IMF plot shown in the top panel of Fig. 1. An interesting possibility is that the step in convection that we observed traveling across the polar cap might be somehow associated with the substorm trigger. The convection step had a peak speed close to $1.1 \mathrm{~km} / \mathrm{s}$ and, (see Fig. 1) passed over Eureka at 08:55 UT. Assuming that it continued to travel at the same speed, it would have been at magnetic latitude about $72^{\circ}$ at the time of the substorm start. Although we have no observational information about the polar cap boundary location at the time of this substorm start, other studies (e.g. Samson et al., 1992) show the nightside open-closed polar cap boundary near $72^{\circ}$ at the start of substorms. 


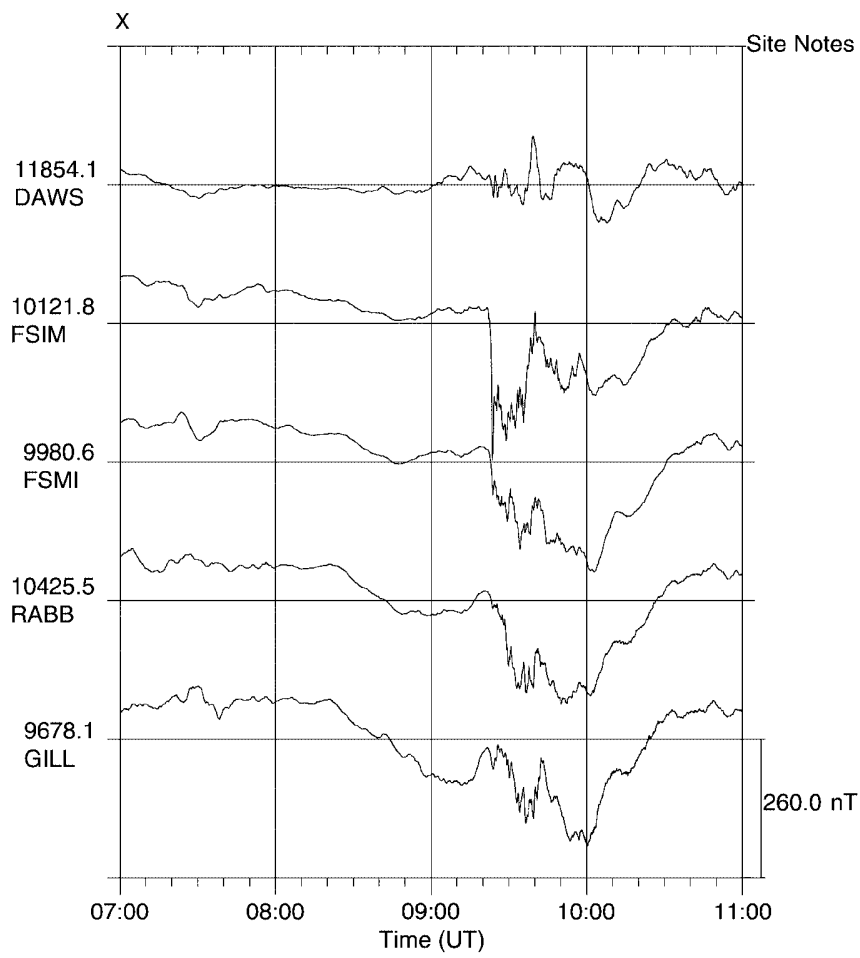

Fig. 7. Horizontal (X) component of the CANOPUS magnetometer array for 22 March, 1997. The stations are DAWS (Dawson), FSIM (Fort Simpson), FMSI (Fort Smith), RABB (Rabbit Lake) and GILL (Gillam)

Thus, we can only suggest the possibility that the arrival of the polar cap transient at the nightside boundary might be associated with the substorm start.

Returning to the pattern of changes shown in Fig. 6, we show the step in convection speed starting from the cusp in Fig. 6b. From the time difference between $t_{a}$ and $t_{c}$, which we have discussed earlier, we can estimate the starting latitude of the step increase in convection, and we can then compare this with the expected latitude of the cusp region. For $t_{a}$ we use the time when we saw the first convection response at Eureka. At Eureka we were measuring the convection and so could directly obtain the time, $t_{c}$. The cusp distance from Eureka was calculated as $\left(t_{c}-t_{a}\right) \times$ (measured $V_{c o n} \max$.). The estimated cusp locations for the 32 events are shown in Fig. 8. The figure also shows the empirical cusp location (solid line) from Newell et al. (1989). The calculated locations are all slightly poleward of the statistical location of Newell et al. (1989). However, we think that the figure shows good agreement allowing for the fact that, as mentioned earlier, our estimation of $t_{a}$ from Eureka might be systematically late by a few minutes. This agreement between the statistical cusp and the inferred location of the velocity increase seems to confirm that the convection step starts at the cusp and then propagates poleward. Therefore, the time of maximum response is not simultaneous at all the polar cap stations. The typical phase speed of the poleward propagation is $\sim 900 \mathrm{~m} / \mathrm{s}$.

The effect of IMF $B_{y}$, which we have not considered in this study, may have significant influence on the

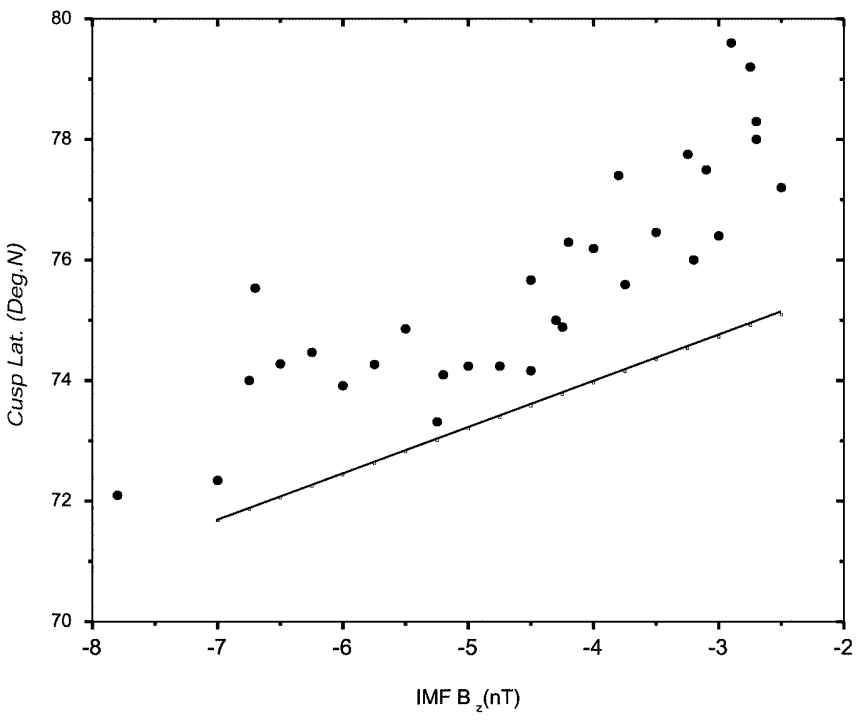

Fig. 8. Location of the cusp for the 32 events calculated using the convection delay (solid circles: see text for details of the calculation) along with statistical fit (solid line) of the poleward boundary of cusp from Newell et al. (1989) for different value of IMF $B_{z}$

delays and the response of the polar cap convection after an IMF turning. The effect of IMF $B_{y}$ is to shift the location of the merging region, and hence the cusp location, to post-noon and pre-noon sectors (Gosling et al., 1991) and this rotates the entire polar cap convection towards earlier (later) local times during positive (negative) IMF $B_{y}$ conditions (Jayachandran and MacDougall, 1999).

Do these patterns of changes that we suggest based on our observations, as illustrated by Fig. 6, agree with some of the current ideas about the nature of polar cap changes for southward IMF turnings? The main current discussion is about the time-history of the development of the 2-cell pattern after a southward turning. There are convincing arguments both for almost simultaneous development of the pattern over the entire polar cap (see Ridley et al., 1999), as well as for the propagation of a developing 2-cell pattern peripherally from the cusp (see Lockwood and Cowley, 1999). Our measurements of central polar cap convection appear to show evidence that both of these patterns of development may be simultaneously present. The events that we studied showed that even in the central polar cap there was a start to the convection response close to the time when the cusp reached its equatorward expansion limit. Following this quasisynchronous start, the central polar cap convection increased progressively. Thus we see a response, during the initial part of the event, that is compatible with the simultaneous response pattern suggested by some of the other studies. However, if the turning of the IMF is sufficiently rapid (as it was for the event shown in Fig. 1 and for the first event in Fig. 3) then we also clearly see, in addition to the progressively developing convection, a step in convection that indicates a propagating pattern of change. Therefore the total response pattern differs depending upon whether the 
turning is rapid or slow. In our Fig. 6 sketches we have attempted to show both the simultaneous development pattern and the propagating features for a rapid IMF change.

It is interesting to speculate whether the travelling step in convection that we observed might somehow be associated with the flow bursts that were studied by Watanabe et al. (1998), and which were observed just prior to substorm onset. The SuperDARN radars did not show echoes from latitudes higher than the auroral region for the event that we studied in detail. Therefore we cannot say whether there were flow bursts associated with this substorm. We plan to return to the question of a possible association of the traveling step in convection and flow bursts in a later study.

On the nightside, our implied patterns of change seems to agree reasonably well with suggestions about the response from Lockwood and Cowley (1999) and from MHD modeling studies by Lopez et al. (1999). For the event of Fig. 1 whose relative times we use in Fig. 6, the nightside auroral expansion started about $35 \mathrm{~min}$ after the IMF turning should have arrived at the cusp ionosphere, or about $20 \mathrm{~min}$ after the cusp expansion was completed. The $20 \mathrm{~min}$ agrees well with the Lopez et al. (1999) modeling.

\section{Conclusions}

During short $(1 / 2-1 \mathrm{~h})$ southward turnings of the IMF in the polar cap we observe the following patterns of convection change: (1) a 2-cell convection pattern that appears to start developing almost simultaneously over much of the polar cap; (2) a delayed convection speed maximum in the central polar cap and (3) a step in convection speed that propagates poleward from the cusp region if the IMF change is sufficiently rapid.

Other observers examining the convection changes on the periphery of the polar cap have reported observations of either quasi-synchronous changes, or propagating changes. Our observations show that the changes have both a quasi-synchronous component and a propagating component.

Acknowledgements. The Editor-in-chief thanks M. Pinnock and T. Moretto for their help in evaluating this paper.

\section{References}

Cannon, P. S., B. W. Reinish, J. Buchau, and T. W. Bullett, Response of polar cap F-region convection direction to changes in the IMF-Digisonde measurements from Northern Greenland, J. Geophys. Res., 96, 1239, 1991.

Cowley, S. W. H., and M. Lockwood, Excitation and decay of solar wind driven flows in the magnetosphere-ionosphere system, Ann. Geophysicae., 10, 103, 1992.

Etamadi, A., S. W. H. Cowley, M. Lockwood, B. J. L. Bromage, D. M. Willis, and H. Luhr, The dependence of high latitude dayside ionospheric flows on the North-South component of IMF, a high time resolution correlation analysis using EISCAT "POLAR" and AMPTE UKS and IRM data, Planet. Space. Sci., 36, 471, 1988.
Fairfield, D. H., Average and unusual locations of Earth's magnetopause and bow shock, J. Geophys. Res., 76, 6700, 1971.

Friis-Christenson, E., Y. Kamide, A. D. Richmond, and S. Matsushita, Interplanetary magnetic field control of high-latitude electric field and currents determined from Greenland Magnetometer data, J. Geophys. Res., 90, 1325, 1985.

Foster, J. C., J. M. Holt, and R. G. Masgrove, Ionospheric convection associated with discrete levels of particle precipitation, Geophys. Res. Lett., 13, 1231, 1986.

Gosling, J. T., M. F. Thomson, S. J. Bame, R. C. Elphic, and C. T. Russell, Plasma flow reversals at the dayside magnetopause and origin of asymmetric polar cap convection, J. Geophys. Res., 95, 8073-8085, 1990.

Grant, I. F., J. W. MacDougall, J. M. Ruohoniemi, W. A. Bristow, G. J. Sofko, J. A. Koehler, D. Daniskin, and D. Andre, Comparison of plasma flow velocities determined by the ionosonde Doppler drift technique, SuperDARN radars, and patch motion, Radio Sci, 30, 1537, 1995.

Heelis, R. A., The effect of interplanetary orientation on dayside high latitude convection, J. Geophys. Res., 89, 2873, 1984.

Heppner, J. P., Empirical model for high latitude electric field, J. Geophys. Res., 82, 1115, 1977.

Heppner, J. P., and N. C. Maynard, Empirical high latitude electric field models, J. Geophys. Res., 92, 4467, 1987.

Holzer, R. E., and J. A. Salvin, Magnetic flux transfer associated with expansion and contraction of the dayside magnetosphere, J. Geophys. Res., 83, 3831, 1978.

Jayachandran, P. T., and J. W. MacDougall, Seasonal and IMF By effect on the polar cap convection orientation, Geophys. Res. Lett., 26, 975-978, 1999.

Lewis, R. V., M. P. Freeman, A. S. Rodger, G. D. Reeves, and D. K. Milling, The electric field response to the growth phase and expansion phase of a small isolated substorm, Ann. Geophysicae, 15, 289-299, 1997.

Lewis, R. V., M. P. Freeman, and G. D. Reeves, The relationship of HF radar backscatter to the accumulation of open magnetic flux prior to substorm onset, J. Geophys. Res., 103, 26 613, 1998.

Lockwood, M., S. W. H. Cowley, and M. P. Freeman, The excitation of plasma convection in the high latitude ionosphere, J. Geophys. Res., 94, 13 447, 1990.

Lockwood, M., and S. W. H. Cowley, Comment on "A statistical study of the ionospheric convection response to changing interplanetary field conditions using the assimilative mapping of ionospheric electrodynamics technique" by A. J. Ridley et al., J. Geophys. Res., 104, 4387, 1999.

Lopez, R. E., M. Wiltberger, J. G. Lyon, C. C. Goodrich, and K. Papadopulos, MHD simulations of the response of highlatitude potential patterns and polar cap boundaries to sudden southward turnings of the interplanetary magnetic field, Geophys. Res. Lett., 26, 967, 1999.

Mozer, F. S., and P. Lucht, The average auroral zone electric fields, J. Geophys. Res., 79, 1001, 1974.

Newell, P. T., C. I. Meng, and D. G. Sibeck, Some low altitude cusp dependencies on the interplanetary magnetic field, J. Geophys. Res., 94, 8921, 1989.

Rich, F. J., and M. Hairston, Large-scale convection patterns observed by DMSP, J. Geophys. Res., 99, 3827-3844, 1994.

Richmond, A. D., and Y. Kamide, Mapping electrodynamics features of the high latitude ionosphere from localized observations: technique, J. Geophys. Res., 93, 5741-4755, 1988.

Ridley, A. J., Gang Lu, C. R. Clauer, and V. O. Papitashvili, A statistical study of the ionospheric convection response to changing interplanetary magnetic filed conditions using the assimilative mapping of ionospheric electrodynamics technique, J. Geophys. Res., 103, 4023, 1998.

Ridley, A. J., Gang Lu, C. R. Clauer, and V. O. Papitashvili, Reply, J. Geophys. Res., 104, 4393, 1999.

Ruohoniemi, J. M., and R. A. Greenwald, Statistical pattern of high latitude convection obtained from Goose Bay Radar observations, J. Geophys. Res., 100, 21 743, 1995a. 
Ruohoniemi, J. M., and R. A. Greenwald, Observations of IMF and seasonal effects in high latitude convection, Geophys. Res. Lett., 22, 1121, 1995b.

Ruohoniemi, J. M., and R. A. Greenwald, Response of high latitude convection to a sudden southward IMF turning, Geophys. Res. Lett., 25, 2913-2916, 1998.

Samson, J. C., L. R. Lyons, P. T. Newell, F. Creutzberg, and B. Xu, Proton aurora and substorm intensifications, Geophys. Res. Lett., 19, 2167-2170, 1992.

Saunders, M. A., M. P. Freeman, D. J. Southwood, S. W. H. Cowley, M. Lockwood, J. C. Samson, C. J. Farrugia, and T. J. Hughes, Dayside ionospheric convection changes in response to long period Interplanetary magnetic field observations: determination of the ionospheric phase velocity, J. Geophys. Res., 97, 19 372-19 380, 1992.

Senior, C., D. Fontaine, G. Caudal, D. Alcayde, and J. Fontanari, Convection electric field and electrostatic potential over $61^{\circ}<\Lambda<72^{\circ}$ Invariant latitude observed with the EISCAT Radar facility 2, Statistical results, Ann. Geophysicae., 8, 257, 1990.

Shepherd, S. G., R. A. Greenwald, and J. M. Ruohoniemi, A possible explanation for rapid, large scale ionospheric response to southward turnings of the IMF, Geophys. Res. Lett., 26, 3197, 1999.
Siscoe, G. L., and T. S. Huang, Polar cap inflation and deflation, J. Geophys. Res., 90, 543-547, 1985.

Spreiter, J. R., and S. S. Stahara, A new predictive model for determining solar wind terrestrial planet interactions, J. Geophys. Res., 85, 6769-6777, 1980.

Todd, H., S. W. H. Cowley, M. Lockwood, D. M. Willis, and H. Luhr, Response time of high latitude dayside ionosphere to sudden changes in the north south component of the IMF, Planet. Space. Sci., 36, 1415-1428, 1988.

Voronkov, I., E. Friedrich, and J. C. Samson, Dynamics of the substorm growth phase as observed using CANOPUS and SuperDARN instruments, J. Geophys. Res., 104(A12), 28 491$28505,1999$.

Watanabe, M., M. Pinnock, A. S. Rodger, N. Sato, H. Yamagishi, A. S. Yukimatu, R. A. Greenwald, J. P. Villain, and M. Hairston, Localized activation of the distant tail neutral line just prior to substorm onsets, J. Geophys. Res., 103, 17 651$17669,1998$.

Weimer, D. R., Models of high latitude electric potential derived with a least error fit of spherical harmonic coefficients, J. Geophys. Res., 100, 19 595-19 607, 1995.

Weimer, D. R., A flexible IMF dependent model of high latitude electric potential having "space weather" applications, Geophys. Res. Lett., 23, 2549-2552, 1996. 